\title{
Absence of 185delAG and 6174delT Mutations among Breast Cancer Patients of Eastern India
}

\author{
Abhijit Chakraborty ${ }^{1}$,Debolina Banerjee ${ }^{1,2}$, Jayasri Basak $^{1 *}$, Ashis Mukhopadhyay $^{3}$
}

\begin{abstract}
Background: The incidence of breast cancer in India is on the rise and is rapidly becoming the number one cancer in females, pushing the cervical cancer to the second position. Most of the predisposition to hereditary breast and ovarian cancer has been attributed to inherited defects in two tumor suppressor genes BRCA1 and BRCA2. Alterations in these genes have been reported in different populations, some of which are populationspecific mutations showing founder effects. Two specific mutations in the BRCA1 (185delAG) and BRCA2 (6174delT) genes have been reported to be of high prevalence in different populations. The aim of this study was to estimate the carrier frequency of 185delAG and 6174delT mutations in eastern Indian breast cancer patients. Materials and Methods: We selected 231 histologically confirmed breast cancer patients from our tertiary cancer care center in eastern India. Family history was obtained by interview or a self-reported questionnaire. The presence of the mutation was investigated by allele specific duplex/multiplex-PCR on genomic DNA extracted from peripheral blood. Results: A total of 231 patients (age range: $26-77$ years), 130 with a family history and 101 without were screened. The two founder mutations 185delAG in BRCA1 and 6174delT in BRCA2 were not found in any of the subjects. This was confirmed by molecular analysis. Conclusions: Our findings suggest that these BRCA mutations may not have a strong recurrent effect on breast cancer among the eastern Indian population. The contribution of these founder mutations to breast cancer incidence is probably low and could be limited to specific subgroups. This may be particularly useful in establishing further pre-screening strategies.
\end{abstract}

Keywords: Breast cancer - BRCA1 - BRCA2 - AS-PCR - exon 2 - exon 11 - Eastern India

Asian Pac J Cancer Prev, 16 (17), 7929-7933

\section{Introduction}

Breast cancer (BC) is a form of cancer in the glandular breast tissue. In India, women diagnosed with carcinoma of the breast is on an average of 80,000 and women die of this disease every year is 40,000 , and it is marked as the second most common cancer among Indian women (19\%) after cervical cancer (30\%) (Saxena et al. 2006). For the development of breast and ovarian cancers there may be several factors responsible, but the presence of BRCA1 and BRCA2 (breast cancer predisposition gene $1 / 2$ ) gene mutations is the most significant which has been described so far .5\%-10\% of the recorded cases accounts for only hereditary breast cancer, in which $80-90 \%$ comprises lifetime risk for the individuals with mutations in these genes of breast cancer and 40-50\% lifetime risk of ovarian cancer (Claus et al., 1991; Easton et al., 1995; Somasundaram 2010). Even after understanding of the fact how BRCA1 and BRCA2 mutations could influence cancer susceptibility which was achieved after several attempts of studies, the variation in risk among carriers of these mutations is not yet clear. It has been noted that the frequency of mutations in these genes is higher in certain groups, as observed in Ashkenazi Jews, where BRCA1/2 mutations are present at a rate of $2 \%-3 \%$ (Neuhausen et al., 1996; Roa et al., 1996; Levy-Lahad et al., 1997). The prevalence of BRCA mutations in asian breast cancer patients is similar in range to that of other ethnic populations (Haeyoung et al., 2013). In this group, 185delAG and 5382insC in BRCA1 and 6174delT in BRCA2 are the three most frequently found mutations, and more than $12 \%$ of the women who develop breast cancer bear one of these mutations (King et al., 2003, Haytural et al. 2013). 25\% mutation in BRCA1 gene of breast cancer patients was identified and reported by Hedau et al. in 2004 from North India. Investigations on the genetic polymorphisms of BRCA1 and BRCA2 gene in a cohort of 204 Indian breast cancer patients, deleterious frame shift mutation 185DelAG mutation was detected (Thakur and Phadke 2005). A study conducted in breast and ovarian cancer families and sporadic breast cancer patients of Indian origin revealed $185 \mathrm{delAG}$ mutation in patients with family history of breast cancer and no mutation was found in sporadic cases (Kumar et al., 2002). Analysis

${ }^{1}$ Dept. of Molecular Biology, ${ }^{3}$ Dept. of Oncology, Netaji Subhas Chandra Bose Cancer Research Institute, Kolkata, ${ }^{2}$ School of Biosciences and Technology, VIT University, Tamilnadu, India*For correspondence: ncri.molecularbiology@gmail.com; abhijit. drems@gmail.com 
Abhijit Chakraborty et al

of PCR amplicons in members of a family with multiple cases of breast cancer in the BRCA1 gene revealed deletion of AG nucleotide at the 185th position, haplotype analysis suggested an independent origin for this mutation (Saxena et al. 2006). Thus the presence of 185delAG mutation in Indian population has been proved by other studies. The present study was planned to investigate the probable occurrence of 185delAG (BRCA1) and 6174delT (BRCA2) alterations in 231 breast cancer patients of Eastern Indian. Our previous studies identified 5382insC mutation in several families, and a pre-screening approach by allele-specific PCR proved to be efficient and justified (Chakraborty et al., 2013).

\section{Materials and Methods}

Altogether 231 individuals diagnosed with breast carcinoma and receiving treatment in different hospitals of Kolkata and adjuvant cancer care centers were included in the our study. Of these patients, 130 proband were with positive family historyin accordance with the inclusion criteria as described previously (Chakraborty et al., 2013) and the remaining was without family history. Personal history was collected from the selected patient group. 69 age matched normal women (control) as applicable: age, age of menarche, marriage and age at 1st delivery of issue, periods of lactation, age of menopause, type of cancer, duration of disease, treatment and diagnosis were also included in the study.

\section{Sample acquisition and storage}

After obtaining written consent form from each individual, $3 \mathrm{ml}$ peripheral blood sample was collected into EDTA vials and stored at $4{ }^{\circ} \mathrm{C}$. This study was approved by the Ethical Committee of our Institute which follow the guidelines given by the ICMR.

\section{DNA isolation}

DNA isolation was done as per our previous publication (Chakraborty et al., 2013) from $3 \mathrm{ml}$ peripheral blood sample. The quality of the DNA was checked by 0.8 $\%$ agarose gel electrophoresis. The quantity of the DNA was measured spectrophotometrically.

\section{Detection of founder mutation of BRCA gene}

BRCA1 mutation was detected by AS-PCR and direct sequencing. Detection of $185 \mathrm{del} A \mathrm{AG}$ and 6174delT was carried out using the oligonucleotide primers listed in Table 1. In each PCR reaction, $25 \mathrm{ng}$ of genomic DNA was added to $20 \mu \mathrm{l}$ of reaction mixture consisting of 10 $\times$ PCR reaction buffer $(10 \mathrm{mM}$ Tris- $\mathrm{HCl}, \mathrm{pH} 8.3,50 \mathrm{mM}$ $\mathrm{KCl}, 10 \mu \mathrm{g} / \mathrm{ml}$ gelatin), $3.25 \mathrm{mM} \mathrm{MgCl}_{2}, 0.2 \mathrm{mM}$ dNTPs, and $3 \mathrm{U}$ Taq DNA polymerase (B'lore Genei, India). The concentration of primers used was $0.12 \mu \mathrm{M}$. Each PCR reaction consisted of an initial $4 \mathrm{~min}$ at $94^{\circ} \mathrm{C}$, followed by 35 cycles of $94^{\circ} \mathrm{C}$ for $30 \mathrm{sec}, 57^{\circ} \mathrm{C}$ for $30 \mathrm{sec}$, and $72^{\circ} \mathrm{C}$ for $45 \mathrm{sec}$, and a final extension step of $10 \mathrm{~min}$ at $72^{\circ} \mathrm{C}$. Then, $10 \mu 1$ of PCR product was mixed with $2 \mu 1$ of loading

Table 1. Primers Used for Detection of Founder Mutations

\begin{tabular}{llclc}
\hline Gene & Primer Name & Exon & Sequence & Product Size \\
\hline BRCA1 & 1B185 CF & 2 & 5'GGTTGGCAGCAATATGTGAA3' & 335 bp \\
& 1B185 WR & & 5'GCTGACTTACCAGATGGGACTCTC3' & \\
& 1B185MR & & 5'CCCAAATTAATACACTCTTGTCGTGACTTACCAGATGGGACAGTA3' 354 bp \\
BRCA2 & 2B6174 CR & 11 & 5'AGCTGGTCTGAATGTTCGTTACT3' & 151 bp \\
& 2B6174 WF & & 5'GTGGGATTTTAGCACAGCTAGT3' & \\
& 2B6174 MF & & 5'CAGTCTCATCTGCAAATACTTCAGGGATTTTAGCACAGCATGG3' & 171 bp \\
\hline
\end{tabular}

CF- Common Forward; WR- Wild Reverse; MR- Mutant Reverse; CR- Common Reverse; WF- Wild Forward; MF- Mutant Forward

Table 2. Comparison between Patients and Controls

\begin{tabular}{|c|c|c|c|c|c|c|}
\hline \multirow{2}{*}{ Age at Menarche } & \multirow{2}{*}{$\begin{array}{c}\text { Patients } \\
\mathrm{N}(\%)\end{array}$} & \multirow{2}{*}{$\begin{array}{l}\text { Control } \\
\mathrm{N}(\%)\end{array}$} & \multirow[t]{2}{*}{ OR } & \multicolumn{2}{|c|}{$95 \%$ Confidence Interval } & \multirow[t]{2}{*}{ p-Value } \\
\hline & & & & Lower & Upper & \\
\hline$<13$ yrs & $136(58.87)$ & $28(40.57)$ & 2.329 & 1.264 & 4.298 & 0.003 \\
\hline$>13$ yrs. & $73(31.60)$ & $35(50.72)$ & & & & \\
\hline \multicolumn{7}{|l|}{ Onset of Cancer } \\
\hline Premenopausal & 157 (67.96) & --- & --- & --- & --- & --- \\
\hline Post-menopausal & $74(32.03)$ & --- & & & & \\
\hline \multicolumn{7}{|l|}{ Marital Status } \\
\hline Married & $195(84.41)$ & $54(78.26)$ & 1.505 & 0.726 & 3.094 & 0.232 \\
\hline Un-married & $36(15.58)$ & $15(21.73)$ & & & & \\
\hline \multicolumn{7}{|l|}{ Parity } \\
\hline Nulliparous & $48(24.61)^{*}$ & $8(14.81) * *$ & 1.878 & 0.784 & 4.646 & 0.127 \\
\hline Multiparous ( $\geq 1)$ & $147(75.38)^{*}$ & $46(85.18) * *$ & & & & \\
\hline \multicolumn{7}{|l|}{ Age at 1st delivery } \\
\hline$<30$ yrs. & $122(82.99) \#$ & 33 (71.73)\#\# & 1.922 & 0.827 & 4.443 & 0.094 \\
\hline$>30 \mathrm{yrs}$ & 25 (17.00)\# & 13 (28.26) \#\# & & & & \\
\hline \multicolumn{7}{|l|}{ Breast Feeding } \\
\hline Yes & $121(82.31) \#$ & 43 (93.47) \#\# & 0.325 & 0.074 & 1.206 & 0.064 \\
\hline No & $26(17.68) \#$ & 3 (6.52) \#\# & & & & \\
\hline
\end{tabular}

$* \mathrm{~N}=195 ; \# \mathrm{~N}=147 ; * * \mathrm{~N}=54 ; \# \# \mathrm{~N}=46$ 


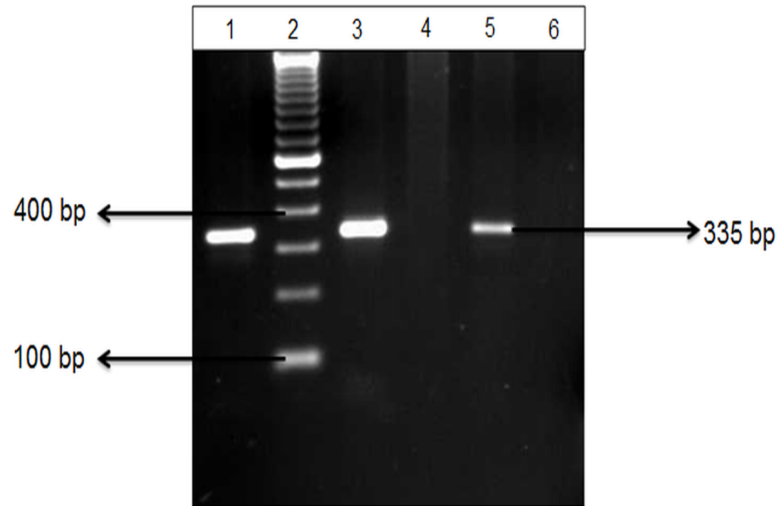

Figure 1. Representative Ethidium Bromide Stained Agarose Gel Photograph of PCR Amplified Product for Detection of the 185delAG Mutation Using an AS-PCR Based Method. DNA was amplified using primer pairs specific for the 185delAG mutant allele or the wild type allele. Lane 1: normal control, lane 2: 100bp DNA ladder, lane 3: sample no. BRCA149 with wild type specific primer, lane 4: sample no. BRCA149 with mutation specific primer, lane 5: sample no. BRCA153 with wild type specific primer, lane 6: sample no. BRCA153 with mutation specific primer. No mutant band was observed

dye and subjected to $3 \%$ agarose gel electrophoresis and finally was visualized after ethidium bromide staining using Bio-Rad Gel Doc. The PCR products were used for direct sequencing from both directions following our previous publication (Chakraborty et al., 2013).

\section{Results}

Average age of the screened patients was $48.40 \pm 11.32$ years (range: 26-77 years). The age of menarche below 13 years in $58.87 \%$ patients and above 13 years in $31.60 \%$ patients were observed. Maximum number of patients (67.96\%) did not experience menopause as they developed cancer at a younger age (premenopausal cancer). Majority of these patients, $84.41 \%(\mathrm{n}=195)$ were married. Among the married patients, $24.61 \%(\mathrm{n}=48)$ patients was nulliparous. Among the parous women, $82.99 \%(\mathrm{n}=122)$ had their first issue below 30 years of age, $17 \%(n=25)$ had their first child above 30 years of age and $82.31 \%$ individuals have practiced breast feeding. Comparison between controls and patients' characteristics i.e., age of menarche, menopausal status, marital status, parity, age at 1 st delivery and breast feeding are shown in Table 2 . The mutation analysis using AS-PCR was performed to detect the presence of 185delAG BRCA1 and 6174delT BRCA2 mutation. The results obtained revealed that no $185 \mathrm{del}$ AG mutation was present in any of the samples analyzed (Fig. 1.). 6174delT was also not present in any sample (Fig.2). None of the 231 patients (with and without family history) carried the $185 \mathrm{del} A \mathrm{AG}$ or $6174 \mathrm{delT}$ mutations. Our analysis was proved by direct DNA sequencing also, which may perhaps explain the absence of the mutation in the samples.

\section{Discussion}

Women, who started menstruating (having periods) younger than the age of 12 years, have a higher risk

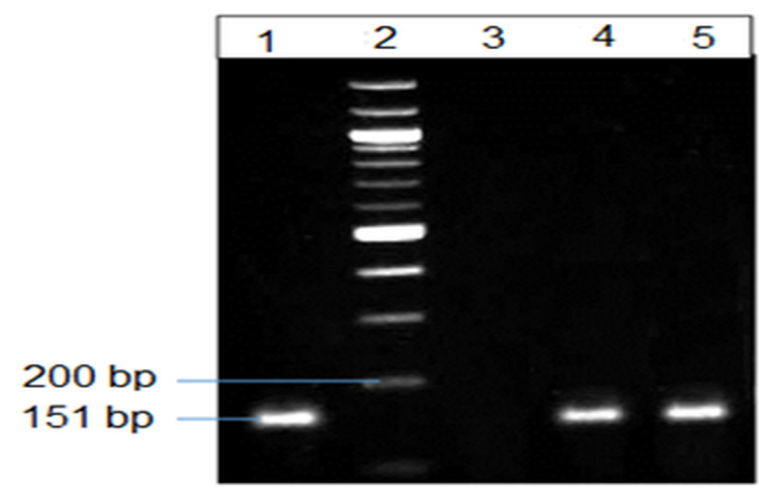

Figure 2. Representative Ethidium Bromide Stained Agarose gel Photograph of PCR Amplified Product for Detection of the 6174delT Mutation using an AS-PCR Based Method.DNA was amplified using primer pairs specific for the 6174delT mutant or the wild type sequence. Lane 1: negative control, lane 2: 100bp DNA ladder, lane 3: NTC, lane 4 \& 5: sample \# BRCA127 \& \# BRCA125 respectively. Duplex PCR was done using $\mathrm{CR}, \mathrm{WF}$ and MF primers. No mutant band was observed

of suffering from breast cancer later in life. The same is true for women who go through menopause when they are older than 55 yrs. In a study by a collaborative group in 2012 on hormonal factors in breast cancer, it was confirmed that early menarche and late menopause increases the risk of having breast cancer. In the present study, there was a significant increase in the patients with menarche before 13 years of age $(\mathrm{p}<0.01$, OR: 2.39; CI: 1.26-4.29) and the mean age of menarche of patients was 13.1 years. We observed that the incidence of pre-menopausal breast cancer is comparatively higher (67.96 \%). In 2002 Mandana Ebrahimi et al. suggested that marital status might have an impact on the incidence of breast cancer. On the other hand, Osborne $\mathrm{C}$ et al. in 2005 described that older married women were at decreased risk for mortality after a diagnosis of breast cancer. No association between BC and marital status of the patients was detected in the present study as there was no significant difference between patients and controls. Women who have given birth to one or more children have half the risk of breast cancer than who have not given birth (Lambe et al., 1996). Marianne Ewertz et al. confirmed that low parity and late age at first birth are significant and independent determinants of breast-cancer risk. Nulliparity was associated with a $30 \%$ increase in risk compared to parous women. In our study, we did not find any association between parity and breast cancer. Age and first live birth $>$ or $=30$ years were associated with an increased relative risk for breast cancer development (Ulusoy et al., 2010). In the present study, there was no significant difference in age at first delivery between patients and controls. Some studies (Gajalakshmi et al., 2009; Babita 2014) show that lack of or less duration of breast feeding is associated with increased risk of breast cancer and lifetime duration of breast feeding is inversely associated with breast cancer risk. There was a borderline significance $(\mathrm{p}=0.06)$ relationship in breast feeding and cancer had been observed in our study.

In this study, 231 Indian breast cancer patients 
Abhijit Chakraborty et al

comprising 130 familial cases and 101 sporadic cases were screened for the presence of $185 \mathrm{delAG}$ of BRCA1 and $6174 \mathrm{delT}$ of BRCA2 mutations using AS-PCR technique. The mutation was not detected in either group. The contribution of mutations in these two genes to breast cancer patients in the Indian population remains relatively unexplored apart from a few studies (Antoniou et al., 2003) In India, 185delAG has been reported in all populations studied (Hansa et al. 2012). This deleterious frame shift mutation was first reported in a family residing in a part of Trivandrum not far from the small towns with settlement of Jewish people. It was later reported in two south Indian families from Kerala province, as well as two sisters from Goa, where a multi-ethnic population exists (Ruffner et al., 2001). The $185 \mathrm{del} A \mathrm{G}$ mutation is one of the common, ancient mutations; it is located at the 5' end of the gene and predicted to cause truncation at the beginning of the zincbinding region of the RING of the putative polypeptide. It was proposed that mutations within the BRCA1 RING domain predispose to cancer by inactivating BRCA1 ubiquitin protein ligase activity (Fodor et al. 1998). The present study provided information on the absence of BRCA1 185delAG and BRCA2 6174delT mutations in a group of Eastern region populations which supports the study from Delhi where Sharma et al. in 2014 reported that the two founder mutations 185delAG, in BRCA1 and 6174delT in BRCA2 were not seen in any of the subjects.

To the best of our knowledge this is the first study to detect these two mutations from Eastern India. The results also suggest that for statistically contribution of this mutation to the breast cancer risk there is a need for studies with larger sample size. In the long run, identification of BRCA1 mutations and other cancer susceptibility genes should permit the development of new and more effective therapies, so that physicians can not only predict future risks, but can reduce those risks reliably and safely before disease occurs. Although we did not find this these mutations our patients, it does not allow us to conclude that it is not present in the Eastern India population. Our findings lend support to the idea that the type and frequency of BRCA1 and BRCA2 mutations are influenced by the geographical and ethnic origins of the population studied.

\section{Acknowledgements}

Authors acknowledge the West Bengal University of Health Sciences, Kolkata to which the institute is affiliated and the patients and their family members for their extensive cooperation and participation in the study. We are grateful to the Indian Council of Medical Research (ICMR), Government of India, New Delhi, India for their financial assistance (File No. 54/07/2011/HUM-BMS; Project Number: 2011-03270).

\section{References}

Antoniou A, Pharoah PD, Narod S, et al (2003). Average risks of breast and ovarian cancer associated with BRCA1 or BRCA2 mutations detected in case Series unselected for family history: a combined analysis of 22 studies. Am J Hum
Genet, 72, 1117-30.

Babita, Kumar N, Singh M, Malik JS, Kalhan M (2014). Breast feeding reduces breast cancer risk: a case-control study in north India. Int J Prev Med, 5, 791-95.

Chakraborty A, Mukhopadhyay A, Bhattacharyya D, et al (2013). Frequency of 5382insC mutation of BRCA1 gene among breast cancer patients: an experience from Eastern India. Fam Cancer, 12, 489-95.

Chakraborty A, Katarkar A, Chaudhuri K, et al (2013). Detection of a novel mutation in exon 20 of the BRCA1 gene, Cell Mol Biol Lett, 18, 631-8.

Claus EB, Risch N, Thompson WD (1991). Genetic analysis of breast cancer in the cancer and steroid hormone study. Am J Hum Genet, 48, 232-42.

Collaborative Group on Hormonal Factors in Breast Cancer (2012). Menarche, menopause, and breast cancer risk: individual participant meta-analysis, including 118964 women with breast cancer from 117 epidemiological studies. Lancet Oncol, 13, 1141-51.

Easton DF, Ford D, Bishop DT (1995). Breast and ovarian cancer incidence in BRCA1-mutation carriers. Breast Cancer Linkage Consortium. Am J Hum Genet, 56, 265-71.

Ebrahimi M, Vahdaninia M, Montazeri A (2002). Risk factors for breast cancer in Iran: a case-control study. Breast Cancer Res, 4, R10.

Ewertz M, Duffy SW, Adami HO, et al (1990). Age at first birth, parity and risk of breast cancer: a meta-analysis of 8 studies from the Nordic countries. Int J Cancer, 46, 597-3.

Fodor FH, Weston A, Bleiweiss IJ, et al (1998). Frequency and carrier risk associated with common BRCA1 and BRCA2 mutations in ashkenazi jewish breast cancer patients. Am J Hum Genet, 63, 45-51.

Gajalakshmi V, Mathew A, Brennan P, et al (2009). Breast feeding and breast cancer risk in India: A multicenter casecontrol study. Int J Cancer, 125, 662-5.

Haeyoung K and Doo HC (2013). Distribution of BRCA1 and BRCA2 mutations in asian patients with breast cancer. $J$ Breast Cancer. 16, 357-65.

Hansa J, Kannan R, Ghosh SK (2012). Screening of 185delAG, 1014delGT and 3889delAG BRCA1 mutations in breast cancer patients from North-East India. Asian Pac J Cancer Prev, 13, 5871-4.

Haytural H, Yalcinkaya N, Akan G, et al (2013). Identification of a novel BRCA2 and CHEK2 A-C-G-C haplotype in Turkish patients affected with breast cancer. Asian Pac J Cancer Prev, 14, 3229-35.

Hedau S, Jain N, Husain SA, et al (2004). Novel germline mutations in breast cancer susceptibility genes BRCA1, BRCA2 and p53 gene in breast cancer patients from India. Br Can Res and Treat, 88, 177-86.

King MC, Marks JH, Mandell JB (2003). Breast and ovarian cancer risks due to inherited mutations in BRCA1 and BRCA2. Science, 302, 643-6.

Kumar BV, Lakhotia S, Ankathil R, et al (2002). Germline BRCA1 mutation analysis in Indian Breast/Ovarian cancer families. Cancer Biol Ther, 1, 18-21.

Lambe M, Hsieh CC, Chan HW, et al (1996). Parity, age at first and last birth, and risk of breast cancer: a population-based study in Sweden. Breast Cancer Res Treat, 38, 305-11.

Levy-Lahad E, Catane R, Eisenberg S, et al (1997). Founder BRCA1 and BRCA2 mutations in Ashkenazi Jews in Israel: Frequency and differential penetrance in ovarian cancer and in breast-ovarian cancer families. Am J Hum Genet, 60, 1059-67.

Neuhausen SL, Mazoyer S, Friedman L, et al (1996). Haplotype and phenotype analysis of six recurrent BRCA1 mutations in 61 families: Results of an international study. Am J Hum 
Genet, 58, 271-80.

Osborne C, Ostir GV, Du X, Peek MK, Goodwin JS (2005).

The influence of marital status on the stage at diagnosis, treatment, and survival of older women with breast cancer. Breast Cancer Res Treat, 93, 41-7.

Roa BB, Boyd AA, Richards CS (1996). Ashkenazi jewish population frequencies for common mutations in BRCA1 and BRCA2. Nat Genet, 14, 185-7.

Ruffner H, Joazeiro CA, Hemmati D, Hunter T, Verma IM (2001). Cancer-predisposing mutations within the RING domain of BRCA1: Loss of ubiquitin protein ligase activity and protection from radiation hypersensitivity. Proc Natl Acad Sci U S A, 98, 5134-9.

Saxena S, Chakraborty A, Kaushal M, et al (2006). Contribution of germline BRCA1 and BRCA2 sequence alterations to breast cancer in Northern India. BMC Med Gen, 4, 75-87.

Sharma S, Rajaram S, Sharma T, et al. (2014) Role of BRCA1 and BRCA2 gene mutations in epithelial ovarian cancer in Indian population: a pilot study. Int J Biochem Mol Biol, $\mathbf{5}, 1-10$.

Somasundaram K (2010). BRCA1 and BRCA1 genes and inherited breast and/or ovarian cancer: benefits of genetic testing. Indian J Surg Oncol, 1, 245-9.

Thakur S, Phadke SR (2005). Familial breast cancer: Genetics and counseling. Indian J Surgery, 67, 297-301.

Ulusoy C, Kepenekci I, Kose K, Aydintug S, Cam R (2010). Applicability of the Gail model for breast cancer risk assessment in Turkish female population and evaluation of breast feeding as a risk factor. Breast Cancer Res Treat, 120, 419-24. 